\title{
SOLIDIFICATION OF SEA ICE
}

\author{
By Clyde M. Adams, fr., David N. French, and W. David Kingery \\ (Ice Research Laboratory, Department of Metallurgy, Massachusetts Institute of \\ Technology, Cambridge, Massachusetts)
}

\begin{abstract}
Aвstract. Thermal considerations affecting the rate of formation of sea ice are discussed showing the effects of the major variables. The natural solidification process (freezing downward from contact with cold air) is contrasted with freezing of layers cast on the surface of sea ice. Transient heating and cooling of solid ice during and after flooding are analyzed. Procedures for maximizing the rate of ice formation and minimizing base-ice heating are discussed, along with factors affecting brine segregation.
\end{abstract}

Résumé. Les auteurs discutent les facteurs thermiques susceptibles d'agir sur la vitesse de formation de la glace de l'eau de mer et signalent le rôle des variables les plus importantes. Le processus naturel de la solidification - au cours duquel la congélation se fait du haut vers le bas par suite du contact avec l'air froid - est comparé avec la congélation de nappes d'eau artificiellement créées à la surface de la glace de mer. Le réchauffement et le refroidissement transitoires des couches solides de la glace soumise à cette inondation sont analysés. Les auteurs suggèrent des méthodes pour accélérer au maximum la formation de la glace et réduire au minimum le réchauffement de la glace sous-jacente, et discutent les facteurs qui déterminent la ségrégation d'eau à salinité élevée pendant la congélation.

Zusammenfassung. Thermische Bedingungen, die die Geschwindigkeit beeinflussen, mit der sich das Meereis bildet, und die Einwirkungen der Hauptvariablen darauf werden besprochen. Der natürliche Verdichtungsprozess (d.h. das Gefrieren nach unten durch Kontakt mit kalter Luft) wird mit dem Gefrieren auf die Meeresoberfläche gepumpter Wasserschichten verglichen. Vorübergehendes Erwärmen und Abkühlen des festen Eises, während und nachdem es unter Wasser gesetzt wird, werden untersucht. Verfahren, die darauf abgezielt sind, die Geschwindigkeit der Eisbildung auf das Maximum zu steigern und das Erwärmen des unten liegenden Eises auf ein Minimum zu bringen, werden besprochen, sowie auch die Bedingungen, die die Salzabsonderung beeinflussen.

\section{Table I. Nomenclature}

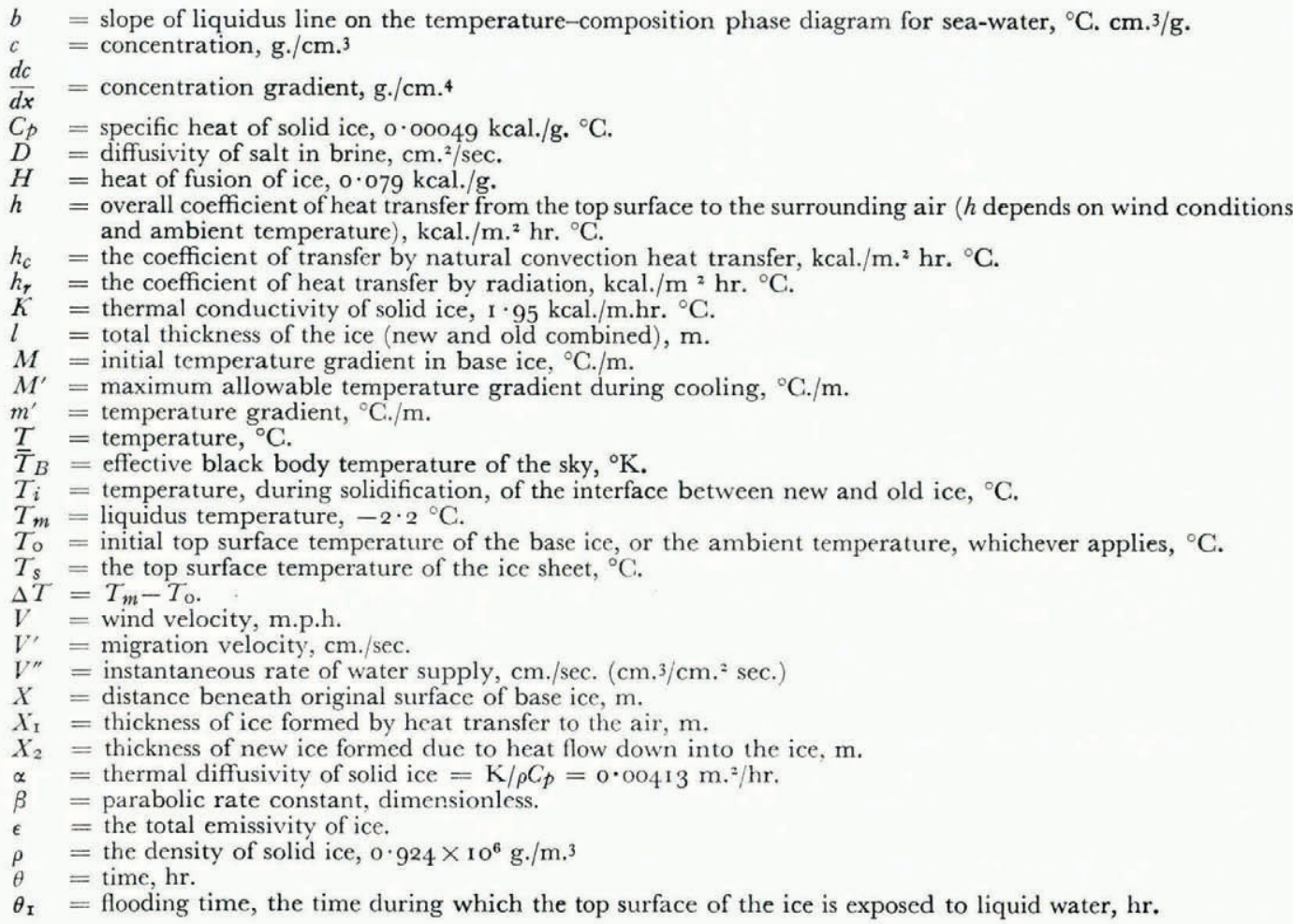




\section{INTRODUCTION}

Since operations in polar regions often depend on the bearing strength of sea ice, the structure, properties, and mode of formation of this material are of much current interest. While the physical and mechanical characteristics of naturally formed sea ice are fairly well understood, development of ways for accelerating and otherwise modifying the solidification process has been limited. The object is to be able to control solidification such that ice of superior mechanical properties can be rapidly produced for engineering applications. There are many possible limitations in this area of applied glaciology ${ }^{\mathrm{I}}$ one which is always present is the thermal regime in which ice is to be formed. The present study has been directed to (I) clarification of basic thermal factors limiting the rate with which ice can be formed under natural as well as artificial conditions, and (2) how freezing and processing mechanisms influence the concentration and distribution of salt in ice.

\section{The Rate of Formation of Ice on Open Water}

In problems involving solidification, the pertinent heat conduction relationships embody the constraint that the liquid-solid interface must move with a velocity proportional to the rate with which heat is withdrawn from that interface. The basic thermal problem is obviously of great practical importance in connection with the casting of fusible materials, and has received much study. ${ }^{2}, 3,4,5$

One quantity which is of paramount importance in describing the pattern of heat flow during solidification of a liquid is the dimensionless parameter $C_{p} \Delta T / H$ where $C_{p}$ is the specific heat of the solid, $H$ is the heat of fusion, and $\Delta T$ is the maximum overall temperature drop in the system. If this dimensionless group is less than 0.3 , as in the case with ice freezing at typical polar temperatures, the conduction of the heat of fusion through the solid ice controls the growth rate; the slight additional heat which must be removed to cool the solid layer below its freezing temperature, can be neglected with little loss in accuracy. Similarly, small amounts of superheat in the liquid have little effect on the freezing rate. (For metals, $C_{p} \Delta T / H$ is often greater than unity and the conduction equations are substantially more complex than for ice.)

The first rigorous analytical treatments of the general problem were derived in connection with polar ice formation by Neumann, 3 Stefan 4,5 and others, who presented the familiar parabolic rate law stating that the thickness of ice formed should be proportional to the square root of freezing time. When freezing takes place from an ice-air interface, the parabolic rate law is predicated on the assumption that growth is limited solely by conduction of heat through the solidified layer, and ignores the resistance to heat transfer encountered at the ice-air interface (i.e. the temperature of the upper surface of the ice is taken as constant and equal to the surrounding air temperature).

To take proper account of convection heat transfer at the ice-air interface, consider that the water is initially at its freezing (liquidus) temperature, and that, during solidification, the temperature gradient is nearly linear through the solid layer. Under these conditions, the rate of heat flow through the solid ice is, at any instant, equal to that from the surface of the ice to the surrounding air, and is proportional to the solidification rate,

$$
\rho H \frac{d X_{\mathrm{I}}}{d \theta}=\frac{\kappa}{X_{\mathrm{I}}}\left(T_{m}-T_{s}\right)=h\left(T_{s}-T_{\mathrm{o}}\right)
$$

Rearranging ( $\mathrm{I}$ ) to eliminate $T_{s}$, we have

$$
T_{m}-T_{\mathrm{o}}=\Delta T=\rho H \frac{d X_{\mathrm{r}}}{d \theta}\left(\frac{x_{\mathrm{I}}}{K}+\frac{\mathrm{I}}{h}\right)
$$

It is not strictly correct to assume a linear temperature distribution through the solid ice, as has been done in deriving Equation (2). In so doing, only the heat of fusion is considered, 
with no provision for the additional heat which must be removed to lower the temperature of the already solid ice. More thorough treatment of the problem yields ${ }^{2}$

$$
\Delta T=\rho H \frac{d x_{\mathrm{I}}}{d \theta}\left(\frac{x_{\mathrm{I}}}{K}+\frac{\mathrm{I}}{h}\right)\left\{\frac{\mathrm{I}+\left(\mathrm{I}+\frac{4 C_{p} \Delta T}{3 H}\left[\frac{Z^{3}-\mathrm{I}}{Z^{3}}\right]\right)^{\frac{1}{2}}}{2}\right\}
$$

where $Z=\left(\frac{h x_{\mathrm{r}}}{K}+\mathrm{r}\right)$.

The final term in brackets in Equation (3) may be regarded as a correction term which takes cognizance of specific heat effects; however, numerical comparison of Equations (2) and (3), as applied to calculation of ice freezing rates, indicates a maximum error of about 7 per cent (usually much less) is to be expected in using the simpler Equation (2). Integration of Equation (2) yields expressions relating ice thickness to freezing time,

$$
\begin{aligned}
& \theta=\frac{\rho H}{\Delta T}\left(\frac{x_{\mathrm{I}}}{h}+\frac{x_{\mathrm{r}}{ }^{2}}{2 K}\right), \\
& \left.x_{\mathrm{r}}=\frac{2 h \theta \Delta T}{\rho H} \mid \frac{\mathrm{I}}{\mathrm{I}+\left(\mathrm{I}+\frac{2 h^{2} \theta \Delta T}{\kappa \rho H}\right)^{\frac{1}{2}}}\right),
\end{aligned}
$$

and, substituting the physical constants for ice,

$$
X_{\mathrm{I}}=\frac{h \theta \Delta T}{36,300}\left\{\frac{\mathrm{I}}{\mathrm{I}+\left(\mathrm{I}+\frac{h^{2} \theta \Delta T}{70,800}\right)^{\frac{1}{2}}}\right\} \text {. }
$$

It can be shown that a maximum error of about 3 per cent results from ignoring specific heat effects in the derivation of Equation $(5 \mathrm{~A})$.

When Equation $(5 \mathrm{~A})$ is used to predict rates of ice formation, it is necessary to know the ambient temperature and the prevailing heat transfer coefficient. If the ambient temperature varies with time over the period of interest, the time average value of ambient temperature can be used rigorously since the instantaneous freezing rate is directly proportional to the overall temperature difference. Thus, the integrated parameter, $\theta \Delta T$ (in ${ }^{\circ} \mathrm{C}$. hr.) can be substituted in Equation $(5 \mathrm{~A})$; this parameter has also been used by Anderson ${ }^{6}$ to correlate a large amount of experimental data. The temperature distribution in the solid ice is linear, with the liquid-solid interface at the liquidus temperature and the top surface temperature expressed as a function of ice thickness by rearranging Equation (I)

$$
T_{s}-T_{\mathrm{o}}=\frac{\Delta T}{\mathrm{I}+\frac{h x_{\mathrm{I}}}{K}} .
$$

In still air, the transfer of heat from the top surface is largely by turbulent natural convection. ${ }^{\text {II }}$ Although there is significant transfer by radiation, the latter is difficult to assess without precise knowledge of the effective sink temperature of the Arctic sky, and the total emissivity of ice.

$$
\begin{aligned}
& h_{c}=0 \cdot 22\left(T_{s}-T_{0}\right)^{\frac{1}{3}}, \\
& h_{r}=\frac{\mathrm{I} \cdot 7 \mathrm{I} \epsilon}{\mathrm{IO}^{9}\left(T_{s}-T_{\circ}\right)}\left\{\bar{T}_{s}^{4}-\bar{T}_{B}{ }^{4}\right\}
\end{aligned}
$$

where $T_{s}$ and $T_{B}$ are absolute temperatures of the surface of ice and the sky.

$$
h=h_{c}+h_{r} \text {. }
$$

Wind in excess of 5 m.p.h. $\left(2 \cdot 2 \mathrm{~m} . \mathrm{sec}^{-1}\right)$ will amplify the convection heat transfer 
coefficient. In this case, any radiation contribution is overwhelmed, and the convection coefficient can be estimated using ${ }^{\mathrm{II}, \mathrm{I} 2, \mathrm{I} 3}$

$$
h=h_{c}={ }_{3} V^{0.8} .
$$

The results of thermal analyses determined on ice solidifying in nearly still air at $-40^{\circ} \mathrm{F}$. $\left(-40^{\circ} \mathrm{C}\right.$.) are shown in Figure I. The curves yield an average value of the overall heat transfer coefficient

$$
h=\text { г о kcal. } / \mathrm{m} \cdot{ }^{2} \mathrm{hr} .{ }^{\circ} \mathrm{C} \text {. }
$$

and exhibit many interesting and important features: (a) During freezing, the top surface temperature of the ice is not constant and is nearer the freezing point of sea-water than the ambient air temperature, (b) the temperature distribution in the solid ice is nearly linear,

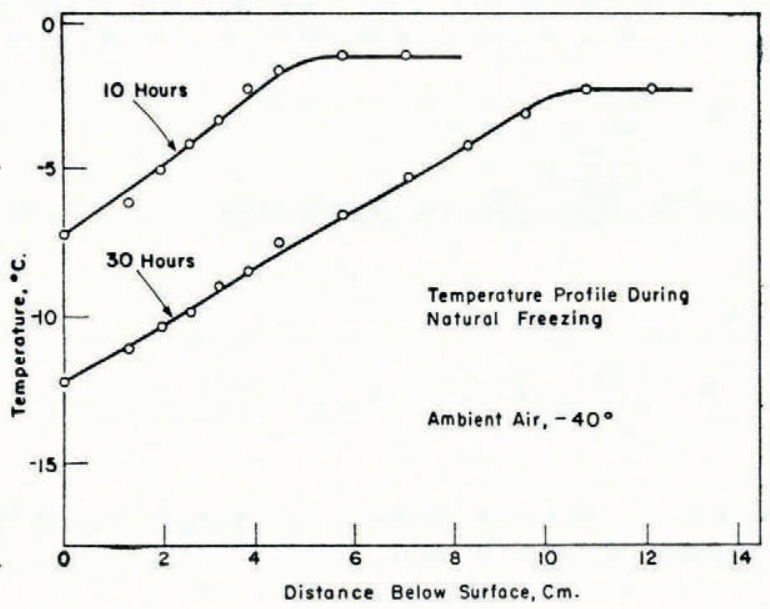

Fig. I. Temperature distributions during solidification of sea-water which has been brought suddenly into contact with cold air. (Measurements made at Eglin Air Force Base while freezing a deep layer; the curves only show that part of the layer which has frozen by transfer of heat upward to the air. The confined liquid suffers some increase in salt concentration and decrease in liquidus temperature with time)

confirming that specific heat terms are relatively unimportant, and (c) during early stages of freezing, the temperature gradient in the solid does not change drastically with time and the solidification rate is nearly constant. When solidification takes place in still air, it is only after the ice thickness exceeds $40 \mathrm{~cm}$. that the parabolic (conduction) term in Equation (4) exceeds the linear (convection) term; in fact, even when the ice has become $120 \mathrm{~cm}$. thick, 25 per cent of the freezing time is attributable to convective resistance at the ice-air interface.

The effect of air movement on the early stages of ice solidification is shown in Figures 2 and 3. Figure 2 relates ice thickness to freezing time, showing the effect of a 15 m.p.h. $\left(6.7 \mathrm{~m}\right.$. sec. $\left.{ }^{-1}\right)$ wind, and, in Figure 3, the same comparison is drawn in terms of freezing rates. From Figure 3 it may be inferred even after $60 \mathrm{~cm}$. of ice have formed, surface convection has substantial influence on the rate of ice formation.

Data of Anderson ${ }^{6}$ on natural ice formation, superimposed on Figure 2, indicate a rather high coefficient of heat transfer. Although this may be due to prevailing wind conditions, it should be emphasized that radiation can be important when the air temperature is near freezing, the effective blackbody temperature of the sky is substantially below the air temperature. In fact, ice may form even when the air temperature is above freezing. 5

The relationship given by Zubov ${ }^{7}$ agrees closely with Equation $\left({ }_{5} \mathrm{~A}\right)$ in form, but yields 
somewhat slower freezing rates. Tabata ${ }^{8}$ documents the deviation from the simple parabolic rate low by showing that the rate "constant" increases with time. Theoretical relationships given by Kolesnikov 9 and also Simpson ${ }^{\text {to }}$ consider factors such as snow cover and solar radiation on seasonal ice growth.

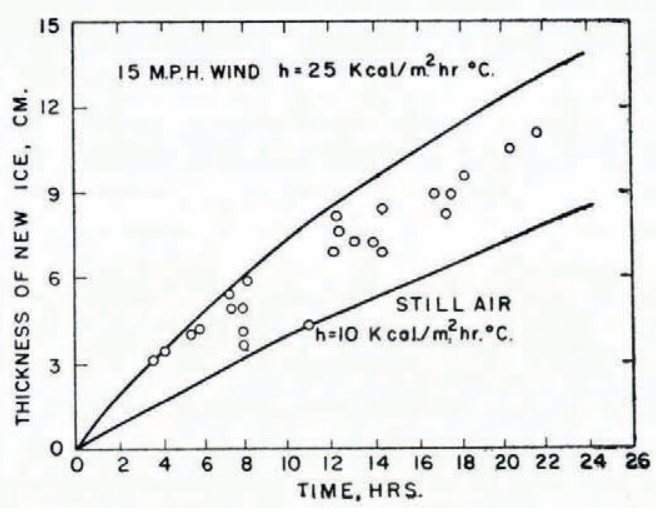

Fig. 2. Ice thickness vs. time $\left(X_{\mathrm{I}}\right.$ vs. $\left.\theta\right)$ sea-water brought into contact with air at $-35^{\circ} \mathrm{C}$. (Curves are drawn using Equation $(5 A)$. Points are data of Anderson $\left.{ }^{6}\right)$

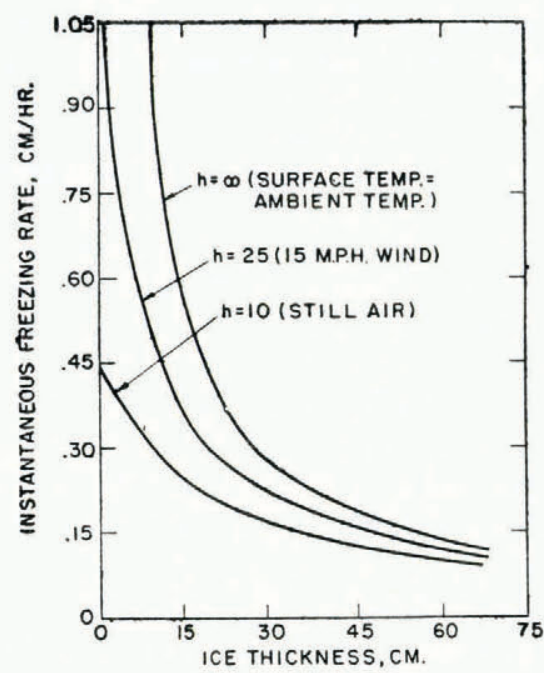

Fig. 3. Freezing rate vs. thickness $\left(d X_{\mathbf{I}} / d \theta\right)$ for sea-water brought into contact with air at $-35^{\circ} \mathrm{C}$.

The thermal reasoning outlined in the above paragraphs has incorporated the concept of a smooth, plane liquid-solid interface, as representing the locus at which all heat of solidification is evolved. This is not the case as shown by the interfacial configuration of a core sample cut from a solidified ice sheet (Fig. 4, p. 76I). When a solution freezes over a temperature range instead of at a discrete melting point, it also freezes over a spatial distribution and not at a discrete plane. To take rigorous account of the way in which heat of fusion is released over a zone of finite breadth, rather than at a plane, greatly complicates the problem, but, happily without significantly modifying the thermal picture. A complete analysis has been done for a metallic solution (aluminum-4 per cent copper alloy) ${ }^{2}$ with the results shown in 
Figure 5, where the temperature distribution which obtains during freezing of a solution is compared with that for pure aluminum. The temperature distribution exhibits a sharp discontinuity at the distinct plane liquid-solid interface in the pure metal, while there is a fairly pronounced "knee" in the region of the liquidus in the alloy. However, the overall picture is not profoundly modified by the presence or absence of the solute (copper), the main effect being upon the liquidus temperature itself.

In a dilute solution, such as sea-water most of the latent heat of fusion is evolved near the liquidus temperature. This is indicated by the heat content versus temperature curve shown in Figure 6; the dotted line represents the approximation embodied in the assumption of discontinuous plane-front freezing. It is to be expected, then, that freezing rates and temperature distributions, calculated as if for pure water, will closely represent the freezing of a dilute aqueous solution, provided the "freezing point" is set equal to the liquidus temperature of the solution.

\section{Freezing of Cast Ice}

When ice solidified upon open water is to be used for bearing purposes, a certain minimum thickness must be developed. It is of interest to produce this thickness as quickly as possible to maximize the useful life of the ice. Since one of the controlling factors is conduction of heat through the solid ice, solidification can be substantially accelerated by "short-circuiting" this heat flow path by transferring water from beneath the ice sheet into contact with the cold top surface and ambient air.

Consider the deposition of a single layer of cold water on top of a thick ice sheet. Heat is transferred from the water down into the cold ice, and up into the ambient air, the two processes taking place simultaneously and independently, until the new layer becomes completely solid. If the base ice on which the layer is to be deposited were initially at some uniform temperature substantially below freezing, the heat-conduction situation is that which has been studied analytically by Schwartz ${ }^{14}$ and Lightfoot ${ }^{15}$ in connection with the freezing of metals in molds.

In this case, the plane at which the cold ice and water are brought into initial contact immediately assumes a femperature intermediate between the freezing point of the liquid and the initial temperature of the cold ice. This temperature remains constant throughout the freezing process, and freezing conforms with the parabolic rate law

$$
X_{2}=2 \beta \sqrt{ }(\alpha \theta)=0 \cdot \mathrm{I}_{2} 9 \beta \sqrt{ } \theta .
$$

In classical treatments of the subject, the parabolic rate constant is evaluated by numerical solution of a cumbersome transcendental equation, ${ }^{2}$, 10, II but for the case of ice formation, may be calculated with an error less than I per cent from

$$
\frac{\mathrm{I}}{\beta}=\frac{H \sqrt{ } \pi}{C_{p} \Delta T}+\frac{2}{\sqrt{ } \pi}=\frac{286}{\Delta T}+\mathrm{I} \cdot \mathrm{I} 29
$$

where $\Delta T$ is the temperature difference between liquidus and initially cold ice.

The temperature at the location of the original ice surface is constant and given by

$$
T_{i}-T_{0}=\frac{H \beta \sqrt{ } \pi}{C_{p}}=286 \beta
$$

where $T_{0}$ is the initial temperature of the base ice.

Since $T_{i}$ is constant, the problem may be conceptually divided into two parts. Heat flow into the base ice is described simply in terms of suddenly raising the surface temperature to $T_{i}$ and holding constant. The temperature distribution in the base ice is then given by

$$
T_{i}-T=\left(T_{i}-T_{\mathrm{o}}\right) \operatorname{erf}\left\{\frac{1}{2} X(\alpha \theta)^{-\frac{1}{2}}\right\}
$$

where erf $a$ is the "error function" of $a, \frac{2}{\sqrt{ } \pi} \int_{0}^{a} \exp \left(-Z^{2}\right) d Z$, a tabulated function.3, 5 
Since specific heat effects are small, the temperature distribution in the layer of new ice is linear, and the rate with which heat flows through the new layer must equal the rate with which heat flows into the base ice, and also be proportional to the solidification rate. In this way, a relationship is developed which parallels Equation (I),

$$
\rho H \frac{d X_{2}}{d \theta}=\frac{K\left(T_{m}-T_{i}\right)}{X_{2}}=\frac{K\left(T_{i}-T_{0}\right)}{\sqrt{ }(\pi \alpha \theta)},
$$

from which Equations (9), (I0), and (I I) can be derived.

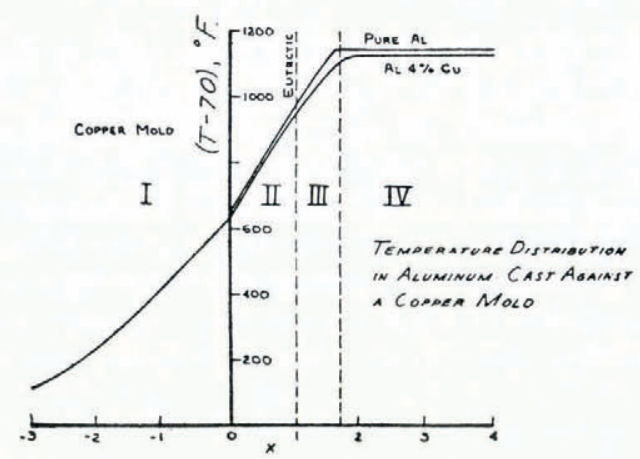

Fig. 5. Freezing of a solution compared thermally to freezing of a pure substance

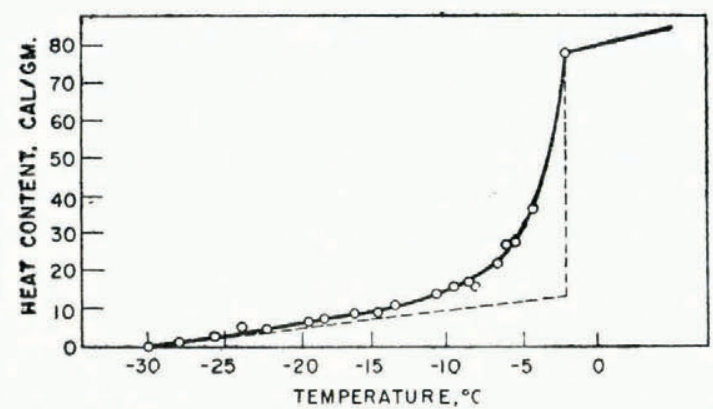

Fig. 6. Heat content vs. temperature for sea-water.

Basis: the phase diagram of Thompson and Nelson ${ }^{17}$;

average specific heat of brine $=0.90 \mathrm{cal} . / \mathrm{g} \cdot{ }^{\circ} \mathrm{C}$.;

average specific heat of ice $=0.49 \mathrm{cal} . / \mathrm{g} .{ }^{\circ} \mathrm{C}$.;

presence of other phases ignored;

heat content taken as zero at $-30^{\circ} \mathrm{C} .(1 \cdot 4 \%$ liquid $)$

In practice, when water is cast onto a thick layer of ice formed by natural solidification, the initial ice is not at uniform temperature. Instead, there is a gradient, $M$, from the freezing temperature at the bottom of the ice sheet to the cold top surface. When an initial linear gradient is present, if the surface of the ice is suddenly heated to $T_{i}$ and held constant, the temperature distribution is given by

$$
T_{i}-T=\left(T_{i}-T_{0}\right) \operatorname{erf}\left\{\frac{1}{2} X(\alpha \theta)^{-\frac{1}{2}}\right\}-M X
$$

where $T_{0}$ is, in this case, the initial surface temperature of the ice. 
The rate of heat flow into the ice can be related to the solidification rate, giving

$$
\rho H \frac{d X_{2}}{d \theta}=\frac{K\left(T_{i}-T_{\mathrm{o}}\right)}{\sqrt{ }(\pi \alpha \theta)}-K M
$$

Equation ( 15 ) is similar to Equation ( ${ }^{3} 3$ ), except that the term, $K M$, has been added, showing that the presence of an initial gradient in the ice sheet has the effect of slowing solidification, negligible at early times but more pronounced as solidification proceeds. Integration of Equation ( 15 ) gives

$$
X_{2}=2 \beta \sqrt{ }(\alpha \theta)-\frac{K M \theta}{\rho H}=0 \cdot 129 \beta \sqrt{ } \theta-\left(2 \cdot 69 \times 10^{-5}\right) M \theta .
$$

The expression, $K M / \rho H$, which appears in Equation (I6), is the rate with which ice is freezing at the bottom of the base ice. In terms of total thickness, then, the second term in Equation (I6) is effectively cancelled. In other words, Equation (9) accurately reflects the total amount of new ice which forms by conduction of heat into the base ice.

- Equations (14) and (I6) are precise to the extent that $T_{i}$ is constant, and that the ice sheet can be considered indefinitely thick. If water were cast on very thick ice, initially at uniform temperature, $T_{\mathrm{o}}$, then $T_{i}$ would indeed be constant. When there is an initial gradient, $T_{i}$ increases somewhat with time, but the effect is not large, because, in fact, $T_{i}$ is never but a few degrees below the freezing temperature, and can never increase beyond the freezing temperature. For example, if $\mathcal{T}_{\circ}$ is $-34.5^{\circ} \mathrm{C}$. and $M$ is $0.263^{\circ} \mathrm{C}$. $/ \mathrm{cm}$., $T_{i}$ starts at $-5.93^{\circ} \mathrm{C}$. and increases slightly during the solidification process.

The only other restriction on Equations (I4) and (I6) is that the ice sheet may be considered infinitely thick so long as $\frac{1}{2} l(\alpha \theta)^{-\frac{1}{2}} \geqslant \mathrm{I} \cdot 5$, where $l$ is the thickness of the base ice, by which time the freezing rate associated with heat flow downward in the ice sheet is so slow as to be no longer of any practical interest. (For example, if $l=120 \mathrm{~cm}$., Equations (I4) and (16) become invalid after $40 \mathrm{hr}$.)

The total thermal picture pertaining to freezing of a single cast layer deposited on a "cold" ice sheet is shown in Figure 7, which gives the temperature distribution prevailing $10 \mathrm{hr}$. after casting $30 \mathrm{~cm}$. of water on a $120 \mathrm{~cm}$. thick sheet of ice in an ambient temperature $-34.5^{\circ}$ C. The curve has been drawn using Equations (5A), ( I A), (9), (10), (I I), and (I 2), and portrays several key features of this solidification system. First, the heat released upon solidification of only $4.1 \mathrm{~cm}$. of ice at the bottom of the layer has drastically heated the base ice, manifesting the relatively low heat-absorbing usefulness of "cold" ice. Second, at the end of $10 \mathrm{hr}$., the amount of ice frozen at the bottom of the new layer roughly equals that frozen from the top. However, the freezing rate from the bottom is decreasing parabolically with time, whereas that from the top is nearly constant, so that when freezing is finally complete, most of the total heat removed to consolidate the layer will have been transferred from the top surface to the air. Third, the original ice surface is heated to a temperature, $T_{i}$, fairly near the liquidus temperature. Fourth, the major surface resistance to heat flow is reflected by the relatively large temperature drop at the ice-air interface.

A case of practical importance is that in which the ice sheet is thickened by sequential deposition of water layers, each of which is allowed to freeze before depositing the next layer. A freezing time for a single layer will depend upon its thickness and also upon whether or not the underlying ice is initially cold, as shown in Figure 8. If layers more than $5^{\circ} \mathrm{I} \mathrm{cm}$. thick are considered, the first layer effectually "uses up" the heat-absorbing capacity of the base ice, and, from that time, all freezing takes place by heat transfer directly to the ambient air, provided each layer is deposited as soon as the preceding layer has become completely solid. Thus, using a predetermined sequence, such as one layer per day, Figure 8 shows how much thicker the first layer can be than the subsequent layers.

After the base ice has been heated by the deposition of the first six or eight centimeters of ice, the maximum average deposition rate depends somewhat upon the layer thickness. In 
Figure 9 it is shown that the maximum possible steady growth rate increases somewhat as the layer thickness decreases. The time space between consecutive deposits is given by the lower curve in Figure 8.

Finally it should be observed the physical picture summarized in Figure 7 reflects accurate thermal book-keeping, but would be distorted somewhat by levitation effects. Some of the ice crystals formed as a result of heat flow downward into the base ice, will detach themselves

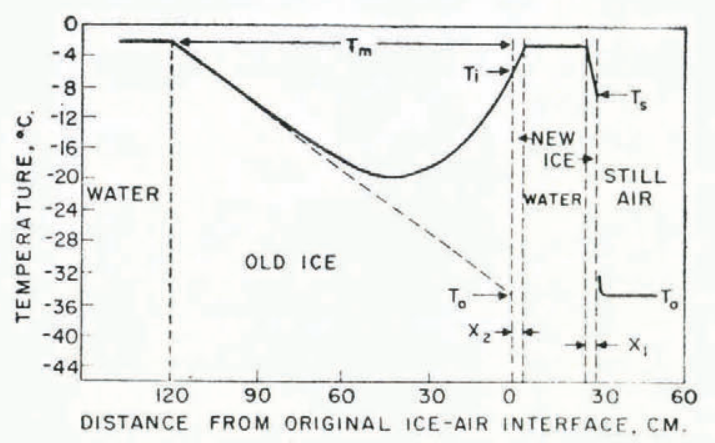

Fïg. 7. Temperature distribution during solidification of a $30 \mathrm{~cm}$. layer of water deposited on "cold" ice, ten hours after flooding

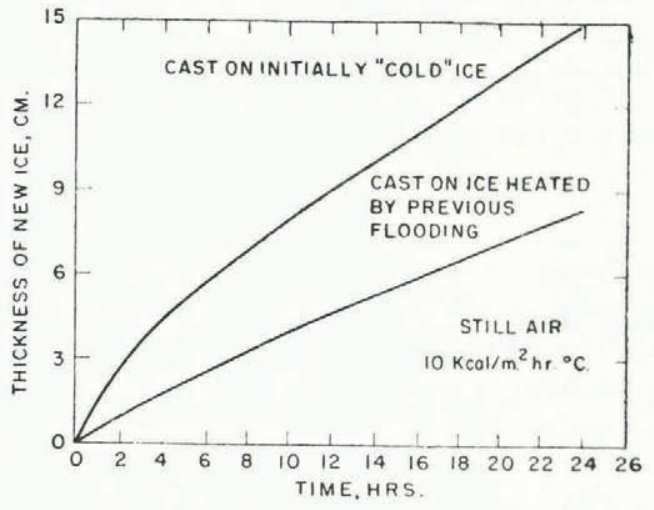

Fig. 8. Layer thickness vs. solidification time $\left(X_{1}+X_{2}\right.$ vs. $\left.\theta\right)$ for freezing in still air at $-35^{\circ} \mathrm{C}$.

and float to the top surface, with the effect of increasing the top thickness, $X_{i}$, and decreasing the bottom thickness, $X_{2}$. However, neither the downward nor upward heat flow rates would be materially influenced by this physical transport process, so that the sum of the two thicknesses, as calculated using Equations $(5 \mathrm{~A}),(9)$, and (10), or Figure 8 will be quite correct.

Heating the Base Ice

The time-temperature history of the base ice during and after flooding operations is of some interest since this potentially influences mechanical strength, thermal strains and salt migration. The way in which the ice sheet heats up during the early stages of flooding has already been described by Equation (14) and portrayed in Figure 7. It has already been 
indicated Equation (I 4 ) is limited to values of $\frac{1}{2} l(\alpha \theta)^{-\frac{1}{2}}$ greater than $\mathbf{I} \cdot 5$. An expression suitable for long periods of time (limited to $\frac{1}{2} l(\alpha \theta)^{-\frac{1}{2}}$ less than $I^{\cdot} 5$ ) is

$$
T_{m}-T=\left(T_{m}-T_{i}\right) X / l+\left(T_{1}-T_{0}\right) 2 \pi^{-1} \exp \left(-\pi^{2} \theta \alpha / l^{2}\right) \sin \pi(\mathrm{I}-X / l) .
$$

When $\frac{1}{2} l(\alpha \theta)^{-\frac{1}{2}}=\mathrm{I} \cdot 5$, Equations (I4) and (I 7) agree within $\mathrm{I}^{\circ} \mathrm{C}$.

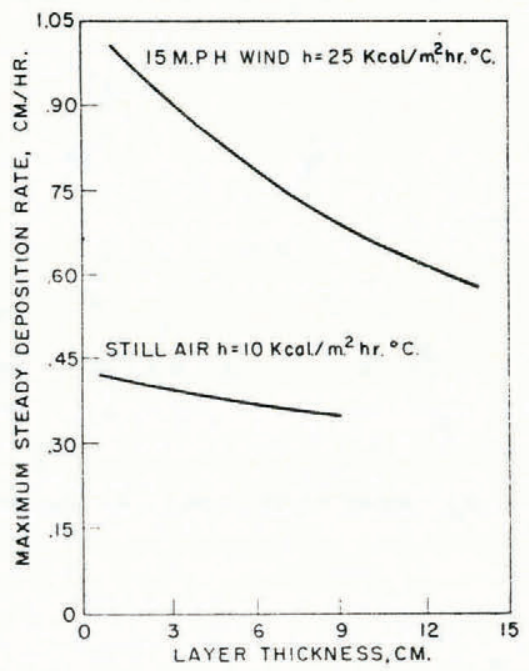

Fig. 9. Maximum deposition rate vs. layer thickness $\left(X_{1} / \theta\right.$ vs. $\left.X_{\mathbf{I}}\right)$

Cooling the Ice

After flooding has proceeded for a long time, and all ice (new and old) is at a temperature not far below the melting point, it is of interest to know how the ice will cool by conduction and convection heat transfer to the ambient air, at $\mathcal{T}_{\mathrm{o}}$, after flooding operations have ceased. During early stages the temperature distribution is represented by $\left(T-T_{0}\right) /\left(T_{m}-T_{0}\right)=\operatorname{erf} \frac{1}{2} X(\alpha \theta)^{-\frac{1}{2}}+\exp \left(h X / K+h^{2} \alpha \theta / K^{2}\right)\left\{\mathrm{I}-\operatorname{erf} \frac{1}{2} X(\alpha \theta)^{-\frac{1}{2}}+h(\alpha \theta)^{\frac{1}{2}} / K\right\}$.

$\theta$ is the time from start of cooling.

Again Equation (18) is valid only when $\frac{1}{2} l(\alpha \theta)^{-\frac{1}{2}}$ is greater than $\mathrm{I}^{\cdot} 5$. The surface temperature during the same period is then given by

$$
\left(T_{s}-T_{\mathrm{o}}\right) /\left(T_{m}-T_{\mathrm{o}}\right)=\exp \left(h^{2} \alpha \theta / K\right)\left[\mathrm{I}-\operatorname{erf}\left\{h(\alpha \theta)^{\frac{1}{2}} / K\right\}\right] .
$$

In Table II is presented a brief set of values from Carslaw ${ }^{2}$ for predicting surface temperatures.

After cooling has progressed to the extent that $\frac{1}{2} l(\alpha \theta)^{-\frac{1}{2}}$ is less than $\mathrm{I} \cdot 5$, the temperature distribution in the ice is given by

$$
\frac{T-T_{\mathrm{o}}}{T_{m}-T_{\mathrm{o}}}=\frac{\mathrm{I}+L X / l}{\mathrm{I}+L}+\frac{2 L \exp \left(-P^{2} \alpha \theta / l^{2}\right) \sin P(\mathrm{I}-X / l)}{\left(L^{2}+L+P^{2}\right) \sin P}
$$

where $L=h l / K$ and $P=L \pi /(\mathrm{I}+L)$.

(The value of $L$ is usually greater than $3 \cdot 0$. If not, then $P$ must be computed as the first root of the equation: $P \cot P+L=0$. This will never be necessary for ice thicker than $60 \mathrm{~cm}$.) 
The surface temperature is

$$
\frac{T_{s}-T_{0}}{T_{m}-T_{0}}=\frac{\mathrm{I}}{\mathrm{I}+L}+\frac{{ }^{2 L} \exp \left(-P^{2} \alpha \theta / l^{2}\right)}{L^{2}+L+P^{2}} .
$$

In Equations (20) and (2 I ), the first terms represent the final, steady state, linear temperature distributions.

In Figure io are shown experimentally determined temperature distributions observed

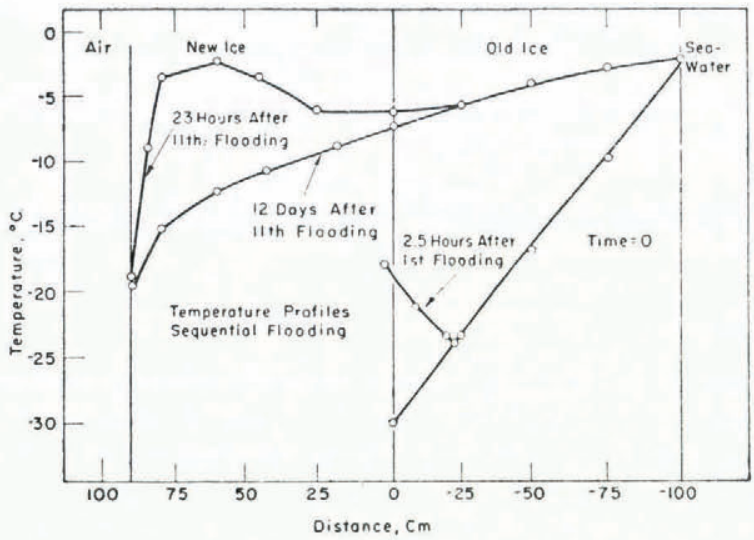

Fig. Io. Temperature distributions measured at Point Barrow by the Naval Civil Engineering Laboratory

before, during, and after flooding operations by U.S. Naval Civil Engineering Laboratory personnel at Point Barrow, Alaska. These curves reflect expected thermal patterns, the important features of which can be reproduced using Equations (17), (18), (20), and (2 I).

Table II. Surface Temperature During Air-Coon.ing of Ice

Initial Temperature $=T_{m}$, Air Temperature $=T_{\mathrm{o}}, \frac{1}{2} l(\alpha \theta) \frac{1}{2} \geqslant 1 \cdot 5$.

$T_{s}-T_{0}$
$T_{m}-T_{0}$
0.8965
0.8090
0.7346
0.6708
0.6157
0.5678
0.5259
0.4891
0.4565
0.4276
0.3785
0.3387
0.3060
0.2786
0.2554
0.2185
0.1905

\begin{tabular}{c}
$h V(\alpha \theta)$ \\
\hline$K$ \\
$0 \cdot 1$ \\
$0 \cdot 2$ \\
0.3 \\
0.4 \\
0.5 \\
0.6 \\
0.7 \\
0.8 \\
0.9 \\
1.0 \\
$1 \cdot 2$ \\
$1 \cdot 4$ \\
1.6 \\
1.8 \\
2.0 \\
2.4 \\
2.8
\end{tabular}

Since the ice structure may be injured by over-rapid cooling, it may eventually become important to establish procedures for controlling the cooling rate, thereby minimizing thermal strains, as is done in the heat treatment of ceramics or metals. For example, if field studies indicate it is desirable to place a maximum value on the allowable surface temperature gradient, one which is substantially less than with natural air cooling, this can be achieved 
by programmed "tapering-off" of the flooding operation. Thus, if cooling is to be done with a constant prescribed surface gradient, the rate of heat flow corresponding to this gradient is subtracted from the rate of heat flow by convection from the surface, and the difference made up by freezing water on the surface

$$
h\left(T_{s}-T_{\mathrm{o}}\right)-K M^{\prime}=H V^{\prime \prime}
$$

where $M^{\prime}$ is the maximum allowable surface gradient, and $V^{\prime \prime}$ the instantaneous rate of water supply.

The surface temperature under this defined circumstance of controlled cooling is given by

$$
T_{m}-T_{s}=2 M^{\prime}(\alpha \theta / \pi)^{\frac{1}{2}}
$$

which, substituted into Equation (22), relates the required water supply to time.

Scrutiny of Equation (22) shows that after

$$
h\left(T_{s}-T_{\mathrm{o}}\right)=K M^{\prime}
$$

the water supply can be ceased altogether, and the ice will continue to cool with shallow gradients.

\section{Short Cycle Flooding}

From the standpoint of trying to optimize structure, salinity, and mechanical properties, some work has been done using flooding times the order of minutes rather than hours, with substantial solid cooling interposed between short flooding cycles. Under these conditions, virtually all heat flow is by conduction downward into the cold base ice, and the initial temperature gradient in the ice sheet, if it is more than $90 \mathrm{~cm}$. thick, has little influence on the solidification rate or thermal fluctuations which result. In this case the time-temperature behavior of the base ice is typified by the experimental curve shown in Figure II. Since freezing from the top surface is negligible in this circumstance, an excess of water can be used, to be removed by squeegees or rollers after the prescribed flooding time has elapsed. The solid ice then cools primarily by conduction downward. The surface temperature drops very rapidly between cycles. After the first cycle, the surface temperature is given by

$$
\frac{T-T_{\mathrm{o}}}{T_{m}-T_{\mathrm{o}}}=\frac{2}{\pi} \sin ^{-1}\left(\theta_{\mathrm{x}} / \theta\right)^{\frac{1}{2}}
$$

where $\theta$ is the total time after initiation of flooding, and $\theta_{1}$ the flooding time. The surface temperature cools only slightly more slowly after the second cycle, the third cycle, etc., and time-temperature cycles such as that portrayed in Figure i i can be developed theoretically by making use of the concept of plane, instantaneous heat sources in the infinite medium.

With respect to solidification rates, it has been found experimentally and confirmed theoretically, using flooding times of $4 \mathrm{~min}$. separated by cooling periods of 16 min., a deposition rate of about $0.3 \mathrm{~cm}$. per layer can be sustained over a four- or five-hour period in an ambient temperature of $-35^{\circ} \mathrm{C}$. to $-40^{\circ} \mathrm{C}$.

\section{Brine Segregation}

It is widely recognized the solidification of sea-water is accompanied by complete segregation of dissolved salt on a local scale (microsegregation) and fairly pronounced macrosegregation as well. Microsegregation is the necessary result of the insolubility of salt in solid ice, and macrosegregation is promoted by several factors. (I) Ice crystals are of lower density than water and float. This effects a partial separation and is one reason "young" sea ice has a salinity substantially below that of the water from which it solidified. (2) Concentrated brine, produced in the immediate region of solidification is heavier than the more dilute sea-water, and tends to sink by natural convection. (3) During the freezing of brine, the expansion associated with solidification displaces brine-rich, interdendritic liquid, downward toward the water, or up onto the ice surface. (4) Finally, a small entrapped region of 
liquid brine, surrounded by solid ice, such as may obtain in late stages of solidification, will migrate through the solid ice if there is a temperature gradient, the direction of movement being from cold to warm.

Not all the above effects are quantitatively well-understood, especially since all take place simultaneously. The reasons for migration of brine droplets through solid ice are fairly clear, however. If there is a temperature gradient, and the droplet tries to come into equilibrium with the ice, there must result, in the droplet, a concentration gradient, the cold side being richer in salt than the warm side,

$$
b \frac{d c}{d x}=m^{\prime}
$$

where $d c / d x$ is the concentration gradient, $m^{\prime}$ the temperature gradient, and $b$ the slope of liquidus line on the temperature-composition phase diagram for sea-water. From this

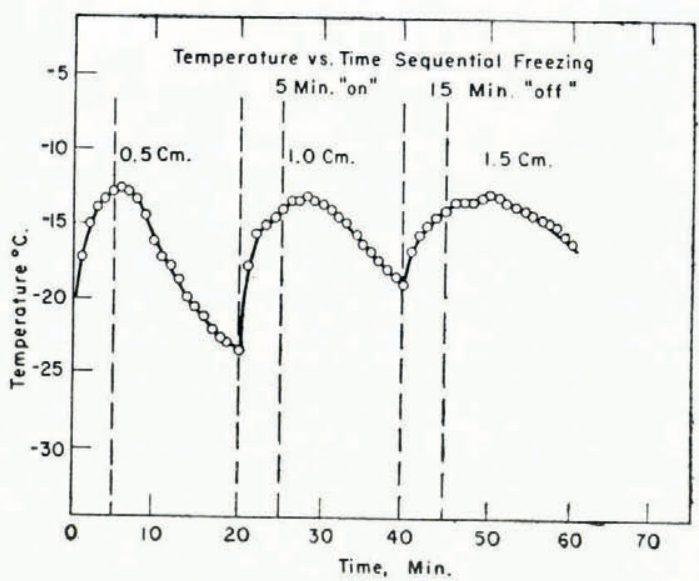

Fig. II. Time-temperature variations at a fixed point in short cycle flooding. ( $\frac{1}{2} \mathrm{~cm}$. per cycle; thermocouple initially on surface; "on" refers to duration of liquid contact, and "off" is cooling period)

migration velocity can be estimated, since diffusion of salt to the warm side of the drop results in melting at a rate which keeps the salt concentration from increasing on that side,

$$
\frac{D d c}{V^{\prime} d x}=C=\frac{-T}{b} .
$$

(In Equation (26), the liquidus is treated as a straight line.) Combining Equations (25) and (26),

$$
V^{\prime}=\frac{D m^{\prime}}{-T}
$$

The diffusivity of salt in water is known from electrochemical data to be the order of $2.4 \times \mathrm{IO}^{-5} \mathrm{~cm}^{2} / \mathrm{sec}$., and, selecting for the temperature gradient $0.5^{\circ} \mathrm{C}$. $/ \mathrm{cm}$. and temperature $-4^{\circ} \mathrm{C}$., the migration velocity is roughly $3 \times \mathrm{IO}^{-6} \mathrm{~cm}$. $/ \mathrm{sec}$. or $0.3 \mathrm{~cm}$. /day, a magnitude consistent with experimental observations. As either the temperature or temperature gradient increases, so does the migration velocity. ${ }^{16}$

The observed salt distribution in a three-inch thick layer of sea ice, solidified on open water in contact with still air at $-40^{\circ} \mathrm{C}$. is shown in Figure 12. However, the distribution 
shown in Figure 12 holds only for that particular instant in time, because mass transport continues to take place throughout the semi-solid layer as solidification progresses, such that the average salt concentration throughout the thickening layer decreases with time, as shown in Figure 13. To take advantage of its relatively low salt content, newly formed ice could be utilized by freezing a surface layer in a sea-water pond, and then mechanically separating the solid ice for deposition elsewhere. This would have the added advantage of separating the heat transfer and deposition sites, and would markedly reduce heating of the base ice. ${ }^{17}$

Short-cycle flooding, removing excess water with squeegees or rollers, such as described in the last section, also gives ice of low salinity as illustrated in Table III. However, the tendency for ice to float and also dendritic freezing interfere with the use of short-cycle flooding as a method for efficient desalination.

$\begin{array}{lcc} & \text { Table III. Salinities } & \\ \text { Type of ice } & & \% \\ \text { Young sea ice } & & 1 \cdot 5 \\ \text { Squeegeed ice } & 2 \cdot 7 \\ \text { Rolled ice } & 0 \cdot 3 \\ \text { Old sea ice } & 3 \cdot 5 \\ \text { Sea-water } & & \end{array}$

\section{Summary}

(I) When ice forms on open water by transfer of heat to the atmosphere, convection at the ice-air interface is of controlling importance in the rate of ice formation. This is especially true during early stages when the thickness is less than $60 \mathrm{~cm}$. Analytical treatment of the problem has yielded expressions for temperature distribution and ice thickness as functions of time which are in accord with experimental findings, and which are greatly simplified by the fact that specific heat effects are of secondary importance in this solidification system.

(2) Limiting rates and times have been derived for the freezing of sea-water cast in sequential layers on top of initially cold sea ice. The effects of the initial temperature gradient in the base ice have been evaluated, and it is shown that a single layer more than 8 or $10 \mathrm{~cm}$. thick will "heat" the base ice to such an extent that if flooding operations are continued heat transfer downward into the solid ice is retarded.

(3) Equations are presented which facilitate analyses of the way in which the base ice is heated and cooled, respectively, during and after flooding perations.

(4) Qualitative review of the many factors influencing the segregation and migration of salt during and after solidification of sea ice has suggested some highly complex mass transfer phenomena which are not well understood and cannot even be ranked according to their relative importance. Much fundamental study will be required to bring the state of knowledge on the chemistry of solidification to the same level as that of thermal phenomena.

(5) Brine segregation during freezing of sea-water is substantial as a result of the insolubility of salt in solid ice. This segregation can be used to effect partial desalination either by freezing a surface layer which can be mechanically separated or by short-cycle flooding with the removal of excess brine by rolling.

\section{ACknowledgement}

This study was carried out at the Arctic Research Laboratory, Point Barrow, Alaska, and at the Climatic Research Laboratory, Eglin Air Force Base, Florida. The support and assistance of Dr. Max Brewer and Mr. C. V. Rychlik of those activities is gratefully acknowledged. Several helpful discussions were held with Colonel L. DeGoes, Arnold Funai, and Earl Moser. The research reported in this article was sponsored by the Geophysics Research Directorate, Air Force Cambridge Research Center, under Contract AF ig (604)3073 with the Arctic Institute of North America.

MS. received ro May 1960 


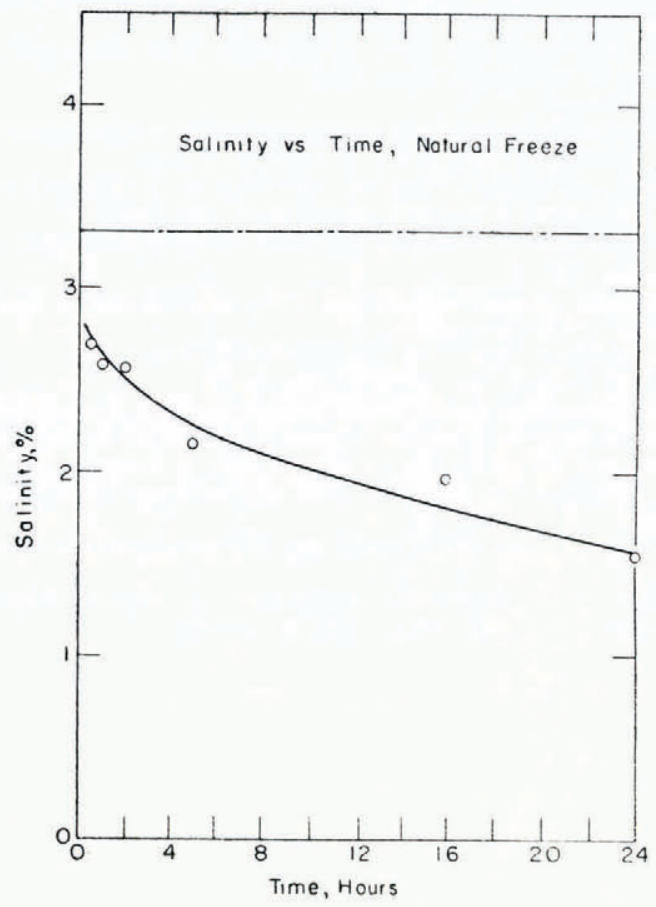

Fig. 12. Salinity distribution in ice layer forming under still air at $-f^{\circ} \mathrm{C}$.

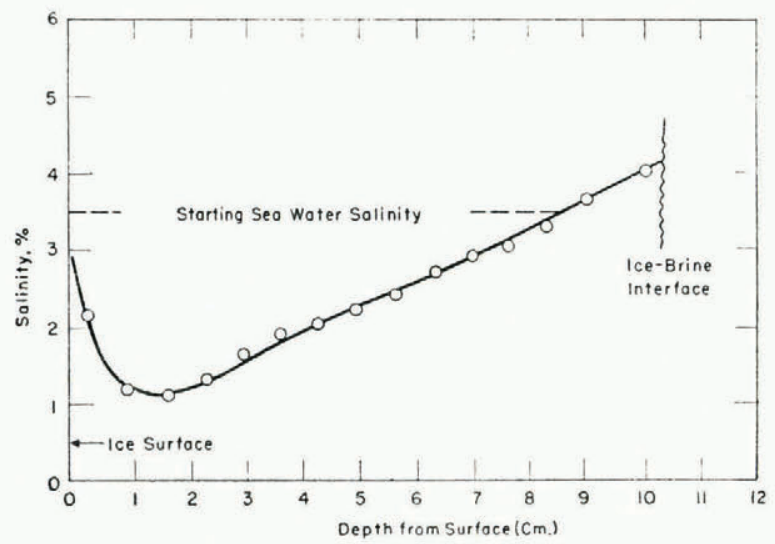

Fig. 13. Average salinity vs. freezing time for young sea ice freezing in still air at $-40^{\circ} \mathrm{C}$.

\section{REFERENCES}

1. Kingery, W. D. Applied glaciology-the utilization of ice and snow in arctic operations. Fournal of Glaciology, Vol. 3 , No. 27 , 1960, p. 577-88.

2. Adams, C. M., jr. Thermal considerations in freezing. (In Liquid metals and solidification. Cleveland, Ohio, American Society for Metals, 1957.)

3. Carslaw, H. S., and Jaeger, J. C. Conduction of heat in solids. Oxford, Clarendion Press, 1947. 
4. Stefan, J. Ueber die Theorie der Eisbildung, insbesondere über die Eisbildung im Polarmeere. Annalen der Physik und Chemie, Bd. 42, Ht. 2, 1891, p. 269-86.

5. Ingersoll, L. R., and others. Heat conduction. By L. R. Ingersoll, O. J. Zobell and A. C. Ingersoll. Revised edition. Madison, Wis., University of Wisconsin Press, 1954.

6. Anderson, D. L. [To be published.]

7. Zubov, N. N. O predel'noy tolshchine morskikh mnogoletnikh l'dov [On the maximum thickness of perennial sea ice]. Meteorologiya $i$ Gidrologiya, Tom 4, No. 4, I938, p. 123-31.

8. Tabata, T. On the formation and growth of sea ice, especially on the Okhotsk Sea. (In Arcli sea ice. Washington, D.C., I958. ([U.S.] National Research Council publ. No. 598.))

9. Kolesnikov, A. G. On the growth rate of sea ice. (In Arctic sea ice. Washington, D.C., 1958. ([U.S.] National Research Council publ. No. 598.))

10. Simpson, L. S. Estimation of sea ice formation and growth. (In Arctic sea ice Washington, D.C., , 1958. ([U.S.] National Research Council publ. No. 598.))

I I. McAdams, W. H. Heat transmission. New York, McGraw-Hill, i 954.

12. Jurges, W. Gesundheitsingenieur, Beiheft 19, Reihe I, 1924, p. I.

13. Knudsen, J. G., and Katz, D. L. Fluid dynamics and heat transfer. New York, McGraw-Hill, I954.

14. Schwarz, C. Zur rechnerischen Behandlung der Erstarrungsvorgänge beim Giessen von Metallen. Zeitschrift für Angewandte Mathematik und Mechanik, Bd. I3, Ht. 3, 1933, p. 202-23.

15. Lightfoot, N. M. H. The solidification of molten steel. Proceedings of the London Mathematical Society, Ser. 2, Vol. 31, r930, p. 97-1 6.

16. Whitman, W. G. Elimination of salt from sea-water ice. American fournal of Science, 5th Ser., Vol. I I, No. 62 , 1926, p. 126-32.

17. Thompson, T. G., and Nelson, K. H. Deposition of salts from sea water by frigid concentration. Sears Foundation Journal of Marine Research, Vol. 13, No. 2, 1954, p. 166-82. 


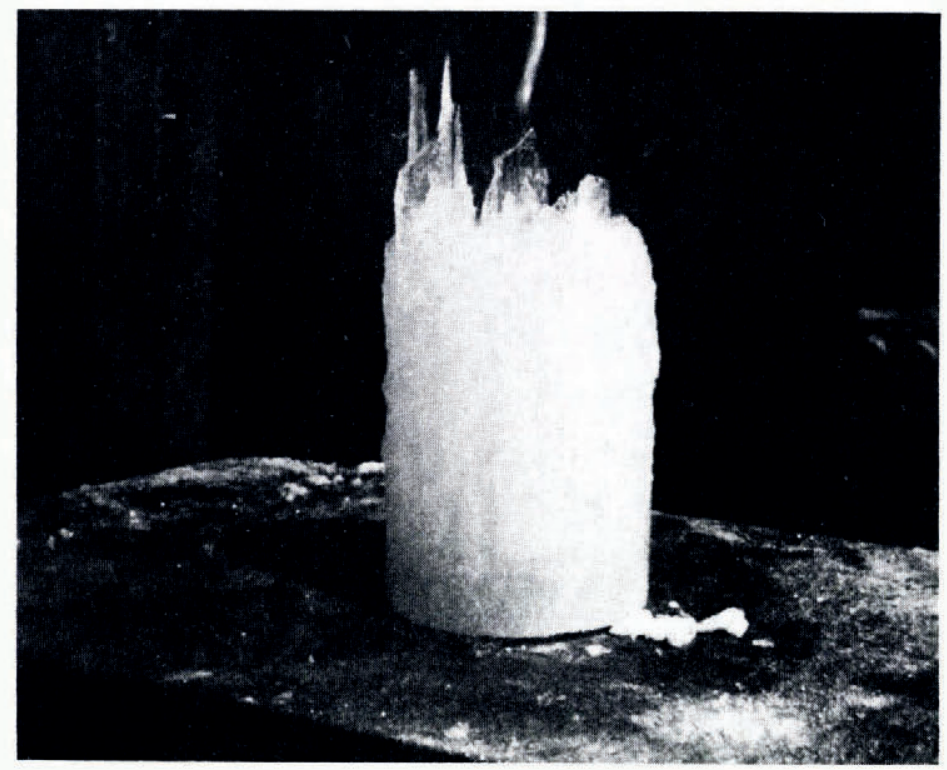

Fig. 4. Core sample removed during solidification showing dendritic, jagged liquid-solid interface. The sample was frozen downward by contact with cold air, and is shown upside down 